\title{
PROCESOS Y PROCEDIMIENTOS DE ORIENTACIÓN VOCACIONAL / PROFESIONAL / LABORAL DESDE UNA PERSPECTIVA SISTÉMICA
}

\author{
Ana Elvira Castañeda Cantillo* \\ Julio Abel Niño Rojas"
}

\section{Resumen}

Esta investigación buscó hacer una descripción de las comprensiones, estrategias y prácticas que identifican el proceso de orientación vocacional / profesional / laboral en la familia y la escuela. Para ello se identificaron los niveles de participación de cada uno de los actores de la organización escolar: estudiantes, docentes, orientadores y padres de familia, se evaluó el impacto de los procesos de orientación profesional, especificando las acciones que se realizan para ello y el papel de los profesionales que lideran el proceso de orientación vocacional / profesional / laboral en las organizaciones escolares.

Mediante un estudio de tipo descriptivo, se aplicó como instrumento una encuesta a orientadores, estudiantes, docentes y padres de familia; las categorías a evaluar fueron: prácticas y nivel de participación en el proceso de orientación, comprensiones y puntuaciones sobre la orientación vocacional / profesional / laboral, efectos e impactos de la orientación, valoración del proceso de orientación, fuentes de influencia en el joven, valoración y recomendaciones de actividades de orientación. Con una muestra de 70 docentes, 35 orientadores, 130 padres de familia y 150 estudiantes de 35 colegios de Bogotá.

Se encontró que los procesos y procedimientos realizados en la orientación vocacional / profesional / laboral están relacionados con presupuestos y acciones fundamentalmente dirigidas a la toma de decisión del estudiante sobre la elección de una carrera universitaria, desde sus intereses individuales, factores económicos e información sobre la oferta; no se observa que haya un acompañamiento para la movilización de los sistemas y contextos familiares, escolares y amplios que involucren procesos pedagógicos, psicológicos, sociales y culturales de los jóvenes con la escuela, la familia y el desarrollo del país.

\section{Palabras clave}

Orientación, vocacional, profesional, laboral, escuela, familia, sistémico.

* Psicóloga, Magíster en Psicológia clínica y de familia de la USTA, integrante del grupo de investigación "Competencias familiares" de la Facultad de Psicología de la USTA.

* Licenciado en orientación y consejería escolar de la Universidad de Pamplona, Psicólogo de la Universidad de la Sabana, Magíster en Psicología clinica y de familia, Docente e integrante del grupo de investigación "Bucleantes", reconocido por Colciencias (2004), del programa de Maestría en Psicológia clínica y de familia de la USTA. 


\begin{abstract}
This investigation looked for to make a description of the understandings, strategies and practices that identify the vocational/professional/labor orientation process in the family and the school. In which were identified the participation levels of each one of the actors of the school organization: students, professors, counselors and family parents, it was evaluated the impact of professional concealing processes, specifying the actions that are carried out for it and the role of the professionals that lead the vocational/professional/labor orientation process in the school organizations.

By means of a study of descriptive type, it was applied as an instrument a survey to counselors, students, teachers and family parents; the categories to evaluate were: practices and participation level in the orientation process, understandings and remarks about the vocational/professional/labor orientation, orientation and impact effects, influence sources on the Youth, valuation and recommendations of orientation activities. With an educational sample of 70 teachers, 35 counselors, 130 family parents and 150 students of 35 schools done in Bogotá.

It was found that the processes and procedures carried out in the vocational/professional/labor orientation are related with budgets and actions fundamentally directed to the student's decision making on the election of an university career, from their individual interests, economic factors and information on the offer; it is not observed that there is an accompaniment for the mobilization of the family context systems, that involve pedagogic, psychological, social and cultural processes of the youths with the school, the family and the development of the country.
\end{abstract}

\title{
Key words
}

Vocational direction, professional direction, labor direction, school, family, systemic.

\section{Introducción}

La organización escolar ha sido el contexto en el que los profesionales dedicados a la "psico-orientación" han trabajado los procesos vocacionales / profesionales / laborales, por lo tanto, se requiere que en este escenario de la formación para la vida de los jóvenes se logren movilizar sus redes en la escuela, la familia y la sociedad, para que desde una mirada sistémico constructivista y ecológica los estudiantes desde su ciclo vital de desarrollo logren tomar las decisiones más pertinentes para su futuro.

Para ello es importante pensar sobre el trabajo con jóvenes, cuyas edades nos muestran que se encuentran en una etapa de su ciclo vital muy particular y que muchas veces la hemos puntuado como "de rebeldía, confusión y crisis hormonal", como algunos autores de la psicología lo manifiestan; sin embargo, resultaría desde esta mirada de los "adolescentes" una paradoja pensar que es en este momento, donde supuestamente están en un mundo "caótico", cuando deben tomar una decisión sobre un aspecto tan importante como lo es la elección de una profesión u ocupación que a futuro marcará su desarrollo personal, familiar y social.

En ese sentido partimos de reconocer a los jóvenes como seres humanos con experiencias de vida importantes y con grandes recursos personales, que están en capacidad de tomar decisiones y de asumir responsablemente sus sueños y retos; por ello, los psicólogos no podemos acompañarlos en sus mundos si los puntuamos 
desde el déficit y lo "anormal"; para acceder a sus mundos, necesitamos entenderlos en sus redes relacionales como protagonistas de historias que nos invitan a los padres, maestros y profesionales en general, a aprender con y de ellos que el mejor escenario para aprender a tomar decisiones en la vida es en lo cotidiano, en el encuentro con el otro y no en espacios artificiales donde sus sueños no emergen.

\section{Referentes contextuales en educación sobre la orientación}

La orientación debe reconocerse en un contexto amplio de la educación, dado que los procesos de orientación están inmersos en el orden social, cultural y económico del país; la orientación es una estrategia en el nivel formal de la educación, donde los estudiantes toman las decisiones profesionales y laborales de acuerdo a un sinnúmero de variables y factores inmersos en el mundo actual y la prospectiva de desarrollo mundial.

La organización educativa secundaria se considera como un momento vital de desarrollo intelectual, afectivo y social donde los jóvenes toman las decisiones sobre su futuro profesional y laboral, y realizan sus decisiones con base en las exploraciones vocacionales que desde la primaria logran reconocer de sí mismos.

La Misión Ciencia, Educación y Desarrollo (1994), “Plantea que el conocimiento, la ciencia y la tecnología se generan, difunden y utilizan casi siempre en organizaciones, como universidades, centros de investigación, institutos tecnológicos y otras instituciones educativas y cada vez más en las empresas... Son las organizaciones las que hacen posible directa $o$ indirectamente que las personas contribuyan con su trabajo al funcionamiento de la sociedad de la cual hacen parte y reciban como retribución una parte del ingreso colectivo".

En la sociedad actual la educación ha ido pasando de un mero lugar de la instrucción formal para las letras y las matemáticas, a un escenario privilegiado por el cual la sociedad contribuye al desarrollo intelectual, físico, ético, afectivo, moral y estético de los individuos; prepara para el trabajo productivo y para el disfrute de los bienes materiales, espirituales y culturales; sirve para mejorar la calidad de vida de los colombianos; $y$ forma para la defensa de los recursos naturales y la preservación del ambiente (Plan Nacional de Educación 1996 2005).

Desde una mirada prospectiva del cambio social se reconoce que ninguna sociedad es completamente estática, por ello se comprende que "el cambio social es un conjunto de alteraciones y transformaciones significativas que afectan de una manera no efímera las estructuras básicas de una sociedad. Estas transformaciones son observables y verificables y afectan la vida de los individuos, de los grupos, de las instituciones y las creencias, costumbres, usos, reglas de comportamiento, valores y símbolos culturales. Esta sucesión de diferencias y variaciones que se dan en distintos ámbitos y niveles de la vida social, se producen sobre un trasfondo de identidad persistente" (Ander, 1998).

El informe de la UNESCO de la Comisión Internacional sobre Educación para el siglo XXI, presidida por Jacques Delors (1996), nos permite visualizar algunas recomendaciones importantes para el proceso de orientación profesional: a) es normalmente mientras cursan la educación secundaria cuando los jóvenes eligen la vía por la que habrán de ingresar a la vida adulta y el mundo laboral; b) la elección de una rama de la enseñaza profesional o general deberá basarse en una evaluación seria que permitirá determinar los puntos fuertes y débiles de los estudiantes; $c$ ) la enseñanza secundaria debe abrirse más al mundo exterior, al tiempo que permite a cada estudiante modificar su trayectoria escolar en función de su evolución cultural y escolar.

El Programa de Naciones Unidas para el Desarrollo elaboró el documento Educación: la agenda de/ siglo XXI (1998), del cual retomaremos algunos planteamientos que nos permiten reconocer la complejidad y la importancia del proceso de la orientación de los jóvenes en el contexto escolar, con sus implicaciones para el desa- 
rrollo de nuestro país. a) Se sigue discutiendo si la educación media debe preparar para la universidad o para el mundo del trabajo, o si debe cumplir ambas funciones simultáneamente; b) Ante la escasez de oportunidades que tienen los bachilleres de ingresar a la universidad, la escuela secundaria les debería brindar más una salida laboral, como una estrategia "propedéutica" para ejercer un oficio determinado; $c$ ) Los jóvenes suelen estar confundidos vocacional y laboralmente, hay un contraste agudo entre la información que reciben y la realidad que confrontan en cuanto a sus posibilidades educativas y ocupacionales; d) la tradicional oferta escolar está en dos vías excluyentes, que son la académica y técnica; no sólo es una expresión de un sistema segmentado según la procedencia económica de los estudiantes, sino que no responde de forma adecuada a los nuevos, requerimientos del mundo laboral, que no busca deberes o destrezas especificas para cierto oficio, sino competencias flexibles para un trabajo más productivo.

Por otro lado, el Programa de Naciones Unidas para el Desarrollo (1998) planteó la importancia de hacer todos los esfuerzos para que la formación se oriente significativamente al mundo del trabajo; para lo cual sugiere lo siguientes aspectos a considerar: a) El levantamiento de un mapa ocupacional consiste en inventariar los oficios existentes en una región o un sector de actividad, y en precisar las dos dimensiones que conforman cada ocupación, esto es: 1) sus tareas o áreas de desempeño, 2) los tipos y niveles de calificación que aplican a dichas tareas. El mapa es una descripción sistematizada del mundo del trabajo y de las competencias laborales como son en un momento y un ámbito determinado; b) Un programa de orientación vocacional democrática debe suministrar a todos la misma información. La secundaria debe mostrar el abanico completo de opciones laborales; c) Un programa de intermediación laboral debe ir más allá del papel marginal y la concepción existencialista. En un mercado cada día más dinámico y más complejo, su contribución a la eficacia y la equidad de los ajustes, es más y más necesaria; d) Análisis sectoriales que revelen las actividades promisorias, las tendencias al crecimiento o la obsolescencia, las inversiones en curso y demás indicadores referentes al empleo y a las necesidades de formación. Por su parte, los análisis ocupacionales permiten conocer los modos de organización del trabajo y establecer los cambios en las competencias laborales.

\section{Perspectivas sobre la orientación vocacional / profesional / laboral}

\subsection{Panorama general de la educación en Colombia}

Rodríguez (2004), coordinador del 1er. Congreso Internacional de Tutores y Consejeros en la Educación Superior, presentó las siguientes cifras: existen 12.500 colegios aproximadamente, los cuales gradúan 430.000 bachilleres cada año; de los cuales solo ingresan unos 140.000 bachilleres a las 328 entidades académicas de carácter superior que existen en el país. La pirámide educativa colombiana nos muestra que relativamente son muy pocos los estudiantes que acceden a la universidad: hay 31.600 establecimientos de nivel preescolar y 57.700 establecimientos de educación básica primaria que tienen alrededor de 6.200 .000 estudiantes; en el nivel de secundaria existen 12.500 colegios con 3.380.000 estudiantes; en el nivel superior las universidades, institutos tecnológicos y técnicos profesionales son 328 y tienen 1.020 .000 estudiantes y en los postgrados están matriculados 57.200 profesionales.

Las cifras nos muestran cómo cada vez que sube el nivel de educación, baja el número de estudiantes; esta situación nos permite reconocer que el acceso a la educación superior es muy limitado para la gran mayoría de jóvenes en nuestro país. Por lo tanto, cuando un joven se equivoca en su elección profesional de una carrera o programa, luego del colegio, está afectándose no solo a sí mismo, sino a todo un sistema cultural y económico que está esperando su aporte en el desarrollo del país. 


\subsection{Orígenes de la orientación vocacio- nal / profesional}

Podemos reconocer que el surgimiento de la orientación vocacional, según Bisquerra (1996), fue en 1908 con la fundación en Boston (EE.UU.) del "Vocational Brueau" y con la publicación de Choosing a vocational de Parsons (1909), apareciendo por primera vez el término de "Vocational guidance" (orientación vocacional). Frank Parsons (1854 -1908), ingeniero y asistente social, se proponía paliar los efectos negativos de la industrialización sobre los jóvenes de clases desfavorecidas mediante la orientación vocacional. En las residencias que creó como un servicio público para ayudar a los jóvenes a buscar trabajo, lo intentaba facilitando un conocimiento de sí mismo, para poder elegir el empleo más adecuado. Se trataba de una actividad fuera del contexto escolar.

En este sentido la orientación tiene aproximadamente 100 años de historia en el mundo si evaluamos sus avances y cambios en las prácticas de orientación, es sorprendente encontrar que las innovaciones y procedimientos de la orientación siguen siendo los mismos a través de estos años.

La concepción en EE.UU. de la orientación fue más centrada sobre los procesos vocacionales y en Europa, donde su surgimiento se dio para la misma época, sin poderse determinar con precisión, se enfatizó más sobre lo profesional (Bisquerra, 1996).

\subsection{Normatividad sobre orientación en Colombia}

Es de reconocer que desde 1932, cuando Mercedes Rodrigo creó el Instituto Psicotécnico, con el fin de brindar asesoría en orientación educativa para elegir la carrera que se adecuara a las capacidades y conocimientos, hasta la fecha, se han dictado innumerables leyes, decretos y resoluciones que servirían como antecedentes para comprender la situación actual de la actividad de la orientación escolar en términos amplios de su concepción y de la orientación vocacional / profesional / laboral del país.
En la resolución número 12712 del 21 de julio de 1982 se reglamentó explícitamente sobre la orientación escolar para los niveles de educación Básica y Media Vocacional, y se asignaron las funciones de los docentes especialistas en esta área. En el Artículo Tercero, se señalan los programas que debe desarrollar el orientador escolar, uno de ellos es la orientación vocacional la cual se expresa: "Programa de orientación vocacional: proporciona información y experiencias que le permitan al estudiante realizar un análisis e interpretación adecuada de su desarrollo vocacional y de sus expectativas educacionales y ocupacionales, con miras a configurar elementos para tomar decisiones vocacionales conscientes y responsables". En el Artículo Séptimo se establece que los profesionales que podrán ser nombrados como orientadores escolares son: Licenciados en Ciencias de la Educación con especialidad en Psicopedagogía o Consejería Escolar, profesionales Magísteres en Orientación Escolar y Psicólogos inscritos en el Escalafón Docente. En el Artículo Octavo se señalan las funciones del orientador escolar, y con respecto a la orientación vocacional se resalta: "Participar en el planteamiento y ejecutar en forma coordinada con los profesores el programa de orientación vocacional, de acuerdo con el plan de estudios del plantel o del núcleo educativo y orientar a los alumnos en la toma de decisiones y asesorarlos en la búsqueda de la información necesaria para tal efecto".

Por otra parte, la Ley 58 del 26 de diciembre de 1983, por la cual se reconoce la Psicología como una profesión y se reglamenta su ejercicio en el país, en el parágrafo del Artículo 11 se establece la función de "orientación y selección vocacional y profesional".

En otro sentido, el Decreto 1850 del 13 de agosto de 2002, mediante el cual se reglamenta la organización de la jornada escolar y la jornada laboral de directivos y docentes de los establecimientos educativos estatales de educación formal, en su Capítulo 2 sobre las actividades educativas de docentes y directivos, en el Artículo 6, sobre el servicio de orientación estudiantil, señala "todos los directivos docentes y docentes deben brindar orientación a sus estudiantes, en forma grupal e 
individual, con el propósito de contribuir a su formación integral, sin que la dirección de grupo implique para el docente de educación básica secundaria y educación media una disminución de su asignación académica de veintidós (22) horas efectivas semanales. No obstante, para apoyar el servicio de orientación estudiantil, en cumplimiento del Artículo 40 del Decreto 1860 de 1994, en las entidades territoriales certificadas podrán asignar los actuales orientadores escolares a las instituciones educativas, según los criterios que defina el ministerio de Educación Nacional".

El decreto 3020 del 10 de diciembre de 2002, por el cual se establecen los criterios y procedimientos para organizar las plantas de personal docente y administrativo del servicio de educación estatal, en el Capítulo 2, sobre los parámetros, en el Artículo 12, sobre orientadores y otros profesionales de apoyo, señala " los orientadores son profesionales universitarios graduados en orientación educativa, psicopedagogía o un área afín, vinculados en propiedad a la planta de personal como docentes o administrativos y que cumplen funciones de apoyo al servicio de orientación estudiantil, no serán tenidos en cuenta para la aplicación de los parámetros establecidos en el artículo 11 del presente reglamento...".

\subsection{Comprensiones sobre el proceso de orientación}

Para Parsons, citado por Bisquerra (1996), la orientación vocacional "es una correcta elección donde hay tres amplios factores: 1) todos los individuos necesitan tener una clara comprensión de sí mismos, de sus aptitudes, intereses, ambiciones, recursos, limitaciones y sus causas; 2 ) un reconocimiento de los requerimientos y condiciones de éxito, ventajas y desventajas, recompensas, oportunidades y perspectivas en diferentes líneas de trabajo; 3 ) un auténtico razonamiento sobre la relación entre estos dos grupos".

González (2001) cita a Fitch (1935), quien define la orientación vocacional como "el proceso de asistencia individual para la selección de una ocupación, preparación para la misma, el inicio y el desarrollo en ella".
Es importante que estas características de la orientación vocacional / profesional / laboral las logremos enmarcar en una realidad legal y contextual de nuestro país; existen actualmente unas reglamentaciones (Decreto 1850 del 13 de agosto de 2002) en las cuales se coloca a los orientadores en una contradicción real de tiempos y espacios para el ejercicio de la función de la orientación vocacional / profesional / laboral de sus estudiantes.

Tovar (2004), retomado la definición etimológica de vocación, la cual viene del latín vocare que significa llamar, define que la vocación es la llamada que cada uno recibe para hacer algo en la vida; refiere que esta llamada viene de la familia, los amigos, los propios gustos y de la publicidad.

Mora (1998) cita a Germain (1980), quien define la orientación profesional como una "actuación científica completa, actual y persistente, destinada a conseguir que cada sujeto se dedique con libertad, pero con conocimiento, al tipo de trabajo profesional para el cual está más dotado, y en el que con menos esfuerzo pueda conseguir mayor rendimiento y mayor provecho, así como mayor satisfacción para sí mismo, al tiempo que el máximo éxito en el ambiente social".

Mora (1998) refiere que se requieren ciertas condiciones para la orientación, dado que en ninguna sociedad humana existen igualdades en el prestigio de las funciones de sus integrantes y unas de ellas son más codiciadas; ni existen miembros de una sociedad donde todos sean aptos para lo mismo. Por lo tanto, es una utopía la creencia de que se puede suprimir la orientación.

Por orientación vocacional comprendemos el proceso mediante el cual los participantes de su red personal y social le facilitan al joven bachiller o de primeros semestres de carrera reconocer sus intereses, aptitudes, valores y actitudes; donde en la vida cotidiana escolar, familiar y social se le permita potencializar y direccionar de acuerdo a las potencialidades y posibilidades de cada uno de estos contextos. 
La orientación profesional, como un proceso mediante el cual se le ayuda a un estudiante bachiller a tomar la decisión de unos estudios técnicos, tecnológicos o universitarios, o en el caso de estar terminando sus estudios de carrera decidir continuar con estudios de posgrado o entrar en el mundo del trabajo, logrando integrar la red personal y social en la cual está inmerso, a la vez que logra reconocer el contexto de desarrollo económico, social y científico en el cual se mueve la sociedad.

Por lo tanto, la orientación laboral hace referencia al proceso mediante el cual se le ayuda un estudiante bachiller que ha recibido orientación vocacional y que por diversas condiciones no puede continuar sus estudios; la elección de un trabajo / empleo está definida por las orientaciones que en su red personal y social logre realizar para formarse para el desarrollo de competencias laborales de acuerdo a las exigencias sociales actuales.

\section{Lecturas sistémicas que facilitan una nueva compren- sión de la orientación}

\subsection{Desarrollo humano}

Si revisamos un poco los planteamientos que la psicología tradicional nos ha mostrado sobre el desarrollo humano, podemos ver que se han caracterizado por una mirada unidireccional, aunque en algunos textos se habla de bidireccionalidad, es decir, se toma en este caso al "joven" como recibiendo y dando una permanente influencia de y a de su medio; con ésta mirada lo estamos considerando como un ser activo, que asume la construcción de su vida de una manera dinámica y propositiva.

Por ello, cuando el joven está dudando de lo que quiere hacer con su vida, en términos de la orientación vocacional / profesional / laboral, centramos su mirada en sus sueños, metas e ideales, pero sería más acertado el proceso si comprendemos que el joven se encuentra inmerso en múltiples sistemas y sobre todo en las relaciones que se están dinamizando al interior de ellos.

Como lo plantea Bronfenbrenner (1987), no podemos comprender el desarrollo humano aislando al individuo de sus contextos, siempre tenemos que considerarlo en una permanente interacción con ellos.

Al referirnos a interacción, quisiéramos precisar una idea en relación con la descomposición de la palabra "interacciones", es decir, acciones entre individuos, entre sistemas, entre miembros del colegio, la familia y la sociedad; donde cada acción, al afectar la acción del otro, se ve a sí misma afectada por esa acción del otro. Desde esta perspectiva, lo que pasa entre el joven, el colegio y la familia se vuelve un circuito que en su interjuego de relaciones conforma una primera red de apoyo para el joven en el proceso de toma de la decisión.

\subsection{Ciclo vital familiar}

Dallos (1996), sobre las concepciones de las imágenes de familia y ciclo vital familiar, considera que "Las familias existen en entornos que se modifican constantemente y que exigen de ellas la capacidad de realizar continuos cambios. Una familia es una entidad "orgánica" que, al mismo tiempo que mantiene una forma de identidad y estructura, está permanentemente cambiando y evolucionando. Aparte de las variaciones y de la adaptación necesarias en la vida cotidiana de la familia, es también evidente que las familias tienen a veces que enfrentarse con situaciones que representan una gran exigencia de adaptación a los cambios".

Dallos (1996) cita los planteamientos de Carter y McGoldrick (1980), refiriendo que el "flujo vertical en un sistema incluye patrones de relación y funcionamiento que se transmiten a través de las generaciones familiares. Esto incluye todas las actitudes, tabúes y expectativas de la familia, y todas las cargas con las que crecemos. Alguien ha dicho que estos aspectos de nuestra vida son como las cartas que nos reparten en una parti$\mathrm{da}$, son una realidad; lo importante para nosotros es lo que hacemos con ella. En el flujo horizontal, incluye tanto las presiones que conlleva la evolución y los que 
son previsibles, como aquellos sucesos que no pueden precerse, "Ios caprichos y designios de la fortuna", y que pueden alterar el proceso del ciclo vital".

Haley (1981), señala "que a raíz de la disminución de ceremonias y rituales en las sociedades occidentales, últimamente se ha hecho patente la importancia en cuanto que facilitan las transiciones entre las etapas del ciclo vital. Por encima de todo, examinar los rituales y ceremonias nos muestra que las familias están conectadas de manera inexplicable con todo un mundo social más amplio".

El curso vital de las familias "evoluciona a través de una secuencia de etapas relativamente previsibles $y$, al parecer, bastante universal, pese a las variaciones culturales y sub-culturales. El ciclo vital familiar también esta sujeto a un sinnúmero de variaciones individuales en cuanto al momento en que se producen los cambios y a las estrategias empleadas para afrontarlos, pero estos cambios han sido clasificados de normativos por una razón: gran parte de la raza humana comparte unos relojes biológicos o expectativas sociales similares (por ejemplo, la entrada a la pubertad, la menopausia, el ingreso a la escuela primaria y el retiro del trabajo) y, en consecuencia, no hay mucha variedad con respecto a estos cambios. Las similitudes en el ciclo vital obedecen también a otra razón: las pautas normativas actúan como guía o ideal cultural que, valorado o denigrado, ejerce cierta influencia sobre el modo en que los individuos perciben su vida y, quizá, sobre su conducta en la vida real" (Janes Falicov, 1988).

\subsection{Red social}

Los seres humanos desde su nacimiento forman parte de un conjunto de relaciones interpersonales. El contacto permanente en un tiempo, con unos actores y en un espacio con otros permite que en lo cotidiano vayan construyendo su identidad.

Sluzki (1996) define la red social personal como "el conjunto de seres con quienes se interactúa de manera regular, con quienes se conversa, con quienes intercambiamos señales que nos corporizan, que nos hacen reales". Al mismo tiempo, habla de que esta red se puede delimitar pero de manera artificial, ya que está inmersa en redes más amplias y en constante evolución.

La red social es todo el conjunto de relaciones que cada persona tiene y que comprende una amplia gama de interacciones, las cuales tienen entre sus funciones dotar al hombre de significados e identidad, además de satisfacer sus necesidades en todos los campos y aportar ayuda en las situaciones que representen dificultad, que permitirán posteriormente un paso hacia el cambio.

Partiendo de este análisis, al hablar de orientación vocacional / profesional / laboral consideraremos que en el universo relacional del joven pueden encontrarse recursos cada vez más tangibles, que le permitirán en sus múltiples sistemas encontrar pistas, luces que le potencien la toma de decisión no solo para lo profesional, sino para otras situaciones vitales importantes.

En el modelo de Sluzki (1996), la red social es el universo relacional del individuo, son todos los contextos en los que éste está inmerso (históricos culturales, políticos, económicos religiosos y ambientales, entre otros). En un nivel más específico se toma la red social personal, también llamada micro social o significativa, como la suma de todas las relaciones que un individuo percibe como importantes dentro de su sociedad, la cual contribuye a su propio reconocimiento como individuo y a su imagen de sí.

\section{Procesos de consultoría}

\subsection{Creación de contextos de intervención}

Los orientadores están llamados en las organizaciones escolares a operar como consultores en los diversos escenarios en los cuales participan, por lo tanto el contexto de la orientación vocacional / profesional / laboral es uno de ellos. Se entiende la consultoría como "una estrategia de intervención, que se construye en un contexto profesional, a partir de la interacción entre 
los sistemas consultante y consultor, y es determinada en la solicitud de ayuda o servicio" (Niño, 1997).

Las características que hacen parte de un modelo de intervención y el rol que debe asumir un consultor en la intervención con un sistema consultante, la define Niño (1997) como "la situación de relación de duración breve, en la que los solicitantes exponen su problema o demanda a un experto, y esperan las informaciones e intervenciones necesarias para definir con claridad el problema y para estar en condiciones de elegir las soluciones más adecuadas".

Cuando un orientador define que cada estudiante es un consultante, con el cual llega al acuerdo de generar un proceso de consultoría para que tome sus decisiones profesionales y laborales, debe contemplar el siguiente modelo de intervención, donde se despliega el siguiente procedimiento:

Diseño del contexto, donde se planea a través de identificar con claridad cada uno de los componentes como: el motivo de consulta, escenarios involucrados, estrategias implementadas en la solución, donde el consultor debe tener claro quién y para qué consulta, quién remite y para qué remite, quién y cuál cambio se desea.

Para los profesionales todas las funciones se les delegan en las organizaciones o contexto de trabajo, y existen una serie de tareas asignadas, las cuales están enmarcadas en los principios y misión propias de la organización. Eso no quiere decir que todas esas tareas se conviertan en pretextos o peticiones para la consultoría, es necesario tener claridad en el rol como consultor para trascenderlo en la pertinencia de la demanda, logrando encuadrar aquellas que no necesariamente estén en el ámbito de la consultoría.

Creación del contexto, en este proceso se realiza el encuadre y se determina la relación con el sistema consultante, definido a través de los marcadores de contexto, como son el establecimiento del objetivo, las funciones y roles; se crea un contexto de investigación / orientación vocacional y de intervención / orientación profesional.
Cada escenario que el consultor va construyendo, lo hace con base en unos mapas y guiones que dan cuenta de las hipótesis, principios y estrategias con las que el consultor opera en el escenario. Los problemas o motivos de consulta de los sistemas consultantes en sí mismos no definen el orden de la intervención, tampoco los contextos donde se dan las demandas de ayuda; son las comprensiones y estrategias las que lo determinan, caracterizadas por las explicaciones ecológicas y las acciones contextuales.

Movilización del contexto, se realiza en el ambiente que construye el consultor, y requiere un escenario tanto organizacional como socio-cultural para la intervención, donde se convoquen los diferentes sistemas. La movilización al cambio se da en la definición y redefinición de la demanda y el problema, en las apuestas que se hacen a los objetivos, hipótesis y estrategias de la intervención. Los escenarios que son los espacios que permiten que emerjan los contextos, son creados en los equipos y movilizados en las redes.

En la consultoría se diseñan las intervenciones sistémicas familiares, con una perspectiva ecológica y contextual, donde se movilizan las redes y los equipos. Desde esta perspectiva la concertación de la demanda y la ayuda se hace a través de un servicio profesional de consultoría, definiendo relaciones profesionales, que implican una demanda y a la vez un servicio de ayuda, exigiendo una definición clara del tipo de servicio de ayuda y de la relación que se va a dar.

Cierre del contexto, en el que el consultor realiza una lectura ecológica del caso, donde implementa las técnicas para la movilización contextual del sistema consultante, por lo que es necesario chequear los efectos de las intervenciones y hacer ajustes al proceso mismo según las redefiniciones determinadas.

\subsection{Redes sociales en la consultoría}

Se comprende la red como un sin número de conexiones entre contextos; todas las redes no tienen las mismas metáforas, hay muchas perspectivas de red, tantas como redes de profesionales, de procesos, de significa- 
do y de procedimientos; todas deben dar cuenta ecológica y contextualmente de los elementos conectados. Para Bateson "las fronteras del individuo no están limitadas por su piel sino que incluyen a todos aquellos con los que el sujeto interactúa: familia, entorno físico, etc.".

Para mapear las redes es importante que el orientador pueda hacer las siguientes distinciones y comprensiones de su rol profesional: a) reconocer los contextos en el orden de las relaciones ideológicas como formas especiales de puntuar las realidades de las organizaciones, con el objetivo de no caer en reduccionismos de mapear únicamente sistemas humanos, explorando otros niveles de contextos; b) leer relaciones en el contexto para reconocer los dominios de realidad en un orden cultural, social y afectivo; acompasado con los órdenes instituidos e instituyentes en la organización; c) evidenciar los procesos, pautas que involucran los niveles de contextos en relación al fenómeno de estudio, para conectarlos y pensar qué me dicen desde lo legal, cultural y educativo, y cómo aportan a la mirada contextual del fenómeno.

\subsection{Los equipos en la intervención}

Los equipos se convocan, constituyen y disuelven según las intencionalidades del fin y el contexto en el que tienen sentido. Son grupos de personas que conforman un núcleo de acciones, valores y sentidos de manera coordinada. Cada equipo se caracteriza en su naturaleza por órdenes como: de tipo de saber que poseen, tipo de comunicación utilizado y procesos pautados, todo en el contexto de la dinámica de la historia de la evolución del mismo.

Se debe reconocer el entramado de los elementos que intervienen en una lectura organizacional, los cuales permiten comprender el proceso de la consultoría en el orden institucional. El reconocimiento de la organización es importante para la intervención, ya que determina el sentido de las prácticas en la organización desde un sentido profesional, ético y estético.
La intervención desde la consultoría debe procurar producir un efecto ecológico en la organización, reconociendo el cambio en las relaciones propias de los sistemas involucrados, creando la interacción con los sistemas y contextos desde la reflexión en la creación de los escenarios interventivos.

\section{Planteamiento de la investigación}

\subsection{Planteamiento del problema}

Las organizaciones educativas de nivel superior, como las universidades, institutos tecnológicos y técnicos profesionales, responsables de la formación profesional, cada vez más expresan sus inconformidades por los bachilleres aspirantes a los diferentes programas de formación, atribuyendo limitaciones en su formación académica, en sus competencias de lecto-escritura, inmadurez emocional y afectiva, dificultades en el ajuste a la vida universitaria, dificultades socio-económicas y no claridad en la toma de decisión vocacional, profesional y laboral.

Por su parte, los colegios, las familias, el estado y la empresa, son las instituciones directamente responsables para que los bachilleres logren tomar las decisiones más acordes con ellos mismos, la sociedad, el país y el mundo.

En este sentido, la orientación vocacional / profesional / laboral es un proceso del cual se requiere que cada vez más demos cuenta de sus comprensiones, estrategias y prácticas; de esta manera podemos generar nuevas posibilidades teóricas y técnicas para el orientador escolar.

\subsection{Objetivos}

a. Identificar los niveles de participación de cada uno de los actores de la organización escolar (estudiantes, docentes, orientadores, directivos y padres de familia) en los procesos de orientación vocacional / profesional / laboral. 
b. Evaluar el impacto de los procesos de orientación profesional, identificando las acciones que se realizan para ello.

c. Identificar el papel de los profesionales que lideran el proceso de orientación vocacional / profesional en las organizaciones escolares.

\subsection{Preguntas orientadoras}

a. ¿Cuáles son las comprensiones que predominan en los orientadores de las organizaciones escolares para explicar el sentido de la orientación?

b. ¿Cuáles son las estrategias que utilizan los orientadores de las organizaciones escolares para dar cuenta de las prácticas de la orientación?

c. ¿Cuáles son los impactos del proceso de orientación desde los diferentes actores del contexto escolar?

d. ¿Cómo operan los diferentes actores del contexto escolar, para conformar una red de apoyo al estudiante en la toma de decisión profesional / laboral?

\section{Referentes metodológicos}

\subsection{Tipo de estudio}

La investigación se enmarca dentro de un modelo cualitativo, en tanto que busca organizar los datos obtenidos de las encuestas en categorías que son analizables de acuerdo a los presupuestos con los cuales se concibe la investigación, para posteriormente pasar a un orden analítico que busca la explicación y comprensión de los objetivos y las preguntas de la investigación.

Esta investigación corresponde a un estudio descriptivo en la medida que pretende identificar los diferentes elementos y características que son propios de los procesos de orientación en las organizaciones escolares.

\subsection{Participantes}

La muestra estuvo constituida por 385 actores dentro del contexto educativo de la formación media vocacional (10 y 11 grados), de 16 organizaciones escolares de la ciudad de Bogotá. Los participantes fueron 150 estudiantes de 10 y 11 grado, 70 docentes de diferentes grados, 130 padres de familia de estudiantes de 10 y 11 grados y 35 orientadores.

\subsection{Instrumentos}

Se utilizaron encuestas para cada uno de los actores del contexto escolar (estudiantes, padres, docentes y orientadores), donde las diferentes preguntas buscaron dar cuenta de las siguientes categorías: prácticas del orientador con diferentes actores del contexto escolar; comprensiones sobre la orientación vocacional y profesional; puntuación de los actores sobre el nivel de participación en la orientación; puntuaciones sobre efectos e impactos de la orientación; prácticas de los actores en el proceso de orientación; valoración del proceso de orientación; prácticas del colegio en el proceso de orientación; fuentes de influencia en el joven; puntuaciones de los estudiantes sobre formas de participación de otros actores; puntuaciones de estudiantes sobre prácticas, valoraciones y recomendaciones de actividades de orientación.

\section{Resultados}

\subsection{Participación de cada uno de los actores de la organización escolar en los procesos de orientación vocacional / profesional}

\subsubsection{Estudiantes}

Los estudiantes plantean que participan en una diversidad de actividades como: aplicación de pruebas $68 \%$, visitas universidades $50 \%$, cátedra de orientación profesional $44 \%$, contacto con universitarios $8.6 \%$, conferencias con profesionales $26 \%$, procesos de inmersión en la universidades $8.6 \%$, trabajo con padres de familia $2 \%$, 
entrevista con psicóloga 3.3\%, información escrita 11.3\% y actividad en otras cátedras $8.6 \%$.

Los orientadores, además de estas actividades, señalan la preparación para el ICFES $8.5 \%$, y orientación sexual $8.5 \%$; las actividades se realizan con una mayor tendencia en grados 10 y 11.

Los estudiantes manifiestan que la orientación profesional les sirve para no cometer errores futuros, tomar decisiones para un proyecto de vida y describir sus capacidades personales para lograrlo.

Los estudiantes manifiestan que ellos mismos deben investigar por su cuenta $74.6 \%$, de este porcentaje el $52 \%$ consigue información específica de las carreras.

\subsubsection{Docentes}

Los estudiantes manifiestan que los docentes no participan activamente en su proceso de orientación, lo perciben como una falta de interés en ellos y consideran que sería muy útil su participación (52\%). Los orientadores manifiestan que los docentes no participan activamente $(62.8 \%)$.

Los profesores manifiestan que la orientación profesional está como una cátedra que permite desarrollar habilidades para el crecimiento personal de los estudiantes y además les ofrece información para que ellos tomen las decisiones sobre su orientación profesional; estáliderada por el psicólogo y se trabaja en los grados 10 y 11.

Los estudiantes (46\%) dicen que los docentes deben vincularse más al proceso de orientación profesional, por su experiencia profesional como egresados de universidades y para aterrizarlos con la realidad.

Los profesores (75\%) manifiestan que no hay participación de ellos en el proceso de orientación profesional, a pesar de saber que se hace algo.

\subsubsection{Orientadores}

Los orientadores manifiestan que ellos realizan una gran diversidad de actividades, que distribuidas en orden de importancia de dedicación son: la atención individual de dificultades de estudiantes, miembros de diversos comités y proyectos institucionales, miembros de redes de la comunidad, selección y admisión de estudiantes, apoyo a procesos pedagógicos, talleres de ecuación sexual, entre otras.

Los padres reconocen la participación en la orientación de sus hijos en diferentes actividades. $94.6 \%$ padres manifiestan que les aplican tests, $92.3 \%$ reportan que hacen visitas a universidades y $44.6 \%$ expresan que no están enterados de lo que hace el colegio.

\subsubsection{Padres de familia}

Los estudiantes manifiestan que los padres de familia participan activamente apoyando su decisión, pero con una dedicación en tiempo baja para esto; señalan que una mayor participación de los padres les da seguridad en ellos mismos.

Los padres de familia (96.9\%) plantean que la orientación profesional es una actividad de la que se encarga el colegio y les sirve a sus hijos para decidir que estudiar correctamente, descubriendo sus intereses, gustos y aptitudes.

Los estudiantes (98.6\%) manifiestan sobre los padres de familia que los apoyan porque respetan sus intereses y los escuchan.

Los padres (65.4\%) manifiestan que ellos apoyan en la casa a sus hijos demostrando respeto a su decisión y no imponiendo la de ellos. Los padres $(30.7 \%)$ les consiguen información de las universidades.

Los profesores (57\%) plantean que en términos generales los padres de familia no están involucrados en el proceso de sus hijos y $24.2 \%$ de los profesores señalan que cada vez se involucran más.

Los orientadores (45.7\%) manifiestan que no hacen nada con los padres de familia y el $20 \%$ refiere que hacen actividades de escuela de padres, diferentes a la orientación, con un intensidad horaria entre 2 a 6 horas al semestre. 


\subsubsection{Directivos}

Los orientadores $(74 \%)$ señalan que los directivos no participan activamente en la orientación profesional cuando participan lo hacen principalmente en las ferias universitarias.

Los orientadores refieren que las organizaciones le proporcionan una infraestructura que consta de pruebas, materiales y oficina: con respecto a las pruebas se aprecia como una fortaleza la utilización de éstas para evaluar personalidad, intereses $y$ aptitudes, y una constante preocupación por actualizarlas; sin embargo, de igual manera se encuentra como debilidad la insuficiencia de diversidad de pruebas y hojas de respuestas, y poco tiempo para calificarlas y socializar los resultados con los estudiantes. Con respecto a los materiales, reconocen lo que hay en el colegio, sin embargo refieren la deficiencia y poco presupuesto para la compra de material de apoyo escrito, audiovisual y talleres. En cuanto a la oficina, la mayoría plantea que tienen un espacio físico cómodo e independiente.

Los orientadores manifiestan que las organizaciones le proporcionan unos espacios académicos en términos de tiempos asignados en los horarios de los estudiantes, como una intención del colegio de apoyar al orientador en su gestión, sin ser una política explícita a nivel organizacional; respetan los horarios de la orientación; reconocen la importancia de la orientación para los estudiantes; el número de profesionales en los departamentos es de un orientador, lo que corresponde al 82.8\%; y frente a la capacitación recibida por los orientadores reconocen que el colegio les cede tiempo para cursos libres, les financia algunos cursos, sin embargo, puntúan una falta de presupuesto para su formación.

\subsection{Impacto de los procesos de orienta- ción vocacional / profesional, identi- ficando las acciones que se realizan para ello}

\subsubsection{Estudiantes}

Los estudiantes recomiendan varias acciones que cualificarían el proceso de orientación profesional, entre ellas tenemos: el $\mathbf{9 5 . 3 \%}$ de los estudiantes piden mayor participación de los padres, lo que los haría sentir más valorados y escuchados; aunque, $\mathbf{9 4 . 6 \%}$ de los estudiantes creen que son ellos mismos los que deben asumir la toma de decisión; el $90 \%$ de lo estudiantes solicitan que el proceso sea más personalizado; $y$ el $62.6 \%$ de los estudiantes prefieren iniciar el proceso de orientación por lo menos desde noveno grado.

\subsubsection{Docentes}

Los profesores proponen algunas consideraciones para que su participación sea más activa en el proceso de orientación, señalando: el $47.1 \%$ de los docentes piensan que se deben flexibilizar a los cambios frente a los diferentes estilos de ser jóvenes y diversidad de opciones profesionales; el $40 \%$ de los docentes requieren saber más del proceso para participar más; el $34.2 \%$ de los profesores quieren conocer más las competencias y habilidades de los estudiantes para apoyarlos más en su toma de decisión desde sus cátedras; y el $25.7 \%$ de los profesores proponen trabajar en equipo con el orientador.

Los profesores recomiendan el trabajo del orientador: el $14 \%$ de los profesores piensan que el trabajo del orientador debe ser más personalizado, el $51.4 \%$ de los profesores creen que se debe trabajar en equipo con padres, directivos y profesores, y el $30 \%$ de los profeso- 
res piensan que el proceso de orientación se debe iniciar desde noveno grado.

Los profesores recomiendan a los directivos del colegio sobre el proceso de orientación: trabajar la orientación como un proyecto de investigación $31.4 \%$; que se inicie la orientación antes de décimo grado $31 \%$; y seguimiento más directo sobre el proceso de cada joven $20 \%$.

Los orientadores (77.1\%) consideran que los docentes son una fuente de influencia positiva, entendida como una fuente de modelos, experiencia, liderazgo y vínculos afectivos con los estudiantes; el $22.9 \%$ de los orientadores consideran que se convierten en una fuente negativa al hacer comentarios descalificativos $y$ al asumir un actitud indiferente.

El 48.5\% de los profesores aprecian como fortaleza del proceso de orientación profesional donde se le da al joven mucha información para visualizar diferentes opciones profesionales y se trabaja con ellos para encaminar la decisión. Como debilidades, los profesores preocupación por la situación económica del joven, de las familias y del país $31.4 \%$; por la confusión de los jóvenes por mucha información $18.5 \%$, y observan una falta de interés y poca responsabilidad de los estudiantes en el proceso17.1\%. Dado lo anterior, los profesores sugieren trabajar más personalizadamente $27.1 \%$, un apoyo familiar más claro $22.8 \%$, y realización de convenios entre universidades y colegios para consecución de becas $22.8 \%$.

\subsubsection{Orientadores}

Las criterios de los orientadores para evaluar los efectos e impactos en los estudiantes que actualmente reciben la orientación profesional son: evaluación institucional $25.7 \%$, no se hace formalmente un proceso de orientación $42.8 \%$.

Las estrategias de los orientadores sobre los efectos e impactos en estudiantes egresados del colegio son: 17.1\% lo hace formalmente mediante solicitud a las universi- dades y por intermedio de la asociación de exalumnos, de manera informal, el $42.8 \%$, y el $74.2 \%$ no lo hacen.

\subsubsection{Padres de familia}

Los padres de familia, dentro de sus recomendaciones al colegio, plantean: talleres específicos de orientación para los padres $92.3 \%$, iniciar el proceso de orientación antes del grado décimo $44.6 \%$, y la orientación profesional como proceso personalizado $34.6 \%$.

Los criterios de los padres sobre los efectos e impactos del proceso de orientación en los jóvenes, los describen de la siguiente manera: en términos del desarrollo personal de los hijos, en el sentido de no equivocarse al elegir, $100 \%$; frente a la dimensión económica, como lo es el invertir el dinero en la carrera escogida por sus hijos sin equivocarse, $37.6 \%$; en términos del compromiso social, con la intención de que sus hijos sean útiles y responsables socialmente $33.8 \%$, y con respecto a su rol de padres, ayudarlos a fortalecerse en éste $20.7 \%$.

El orientador $(78.5 \%)$ considera a los padres como una fuente de influencia en el joven de manera negativa, dado que en sus opiniones imperan más sus expectativas; obstaculizan el proceso de la toma de decisión; enfatizan más sobre su apoyo económico, presionando por carreras lucrativas y con prestigio social; y $21.5 \%$ de los orientadores consideran que los padres son una fuente de influencia positiva dado que acompañan y respetan el proceso, y se constituyen en una base afectiva de los estudiantes para que tomen la decisión.

\subsubsection{Amigos}

Los estudiantes sobre el nivel de participación de los amigos, lo valoran positivamente $63.3 \%$, los valoran como francos en sus recomendaciones el $50 \%$ y estiman que los conocen y saben en qué son hábiles el $42.3 \%$.

Los orientadores plantean que la influencia de los amigos en el joven frente a la toma de decisión de la orientación es evidente y significativa, convirtiéndose en una fuente facilitadora cuando están bien informados y una fuente negativa cuando están desinformados. 


\subsubsection{Medios de comunicación}

Los estudiantes puntúan sobre la participación de los medios de comunicación en su proceso de orientación de la siguiente manera: fuente de información actualizada $90 \%$, no reporta información $14 \%$, crea interrogantes y reflexión $8 \%$. Los estudiantes prefieren dedicarle mucho tiempo a los medios de comunicación para buscar información $\mathbf{9 2 . 6 \%}$

\subsection{Papel de los profesionales que lideran el proceso de orientación vocacional / profesional en las organizaciones escolares}

Dentro de las prácticas que realizan los profesionales responsables de la orientación en los colegios, se plantean las siguientes actividades como propias del proceso de orientación vocacional y profesional: aplicación de pruebas, visitas universitarias, cátedra en el colegio, entrevistas y charlas con profesionales, proyectos propedéuticos o de inmersión en la vida universitaria.

Por otra parte, los orientadores participan en otro tipo de actividades, tales como: proyectos de hábitos de estudio, proyectos de orientación sexual, coordinación para el ICFES de los estudiantes de último año, asumir cátedras en el colegio como las de ética y valores, participación en el proceso de selección de estudiantes y docentes, participación en comités institucionales, atenciones de casos individuales cuando los estudiantes tienen dificultades, organización de cumpleaños y celebraciones, apoyo a proceso pedagógicos, representante del colegio en eventos, apoyo a gestión de coordinadores, escuelas de padres, preparación y participación de convivencias, miembro de redes locales.

\section{Discusión: propuesta del pro- ceso de orientación desde una perspectiva de red}

\subsection{De las crisis de orientación en la universidad}

La formación universitaria se ha dividido en ciclos y en cada una de ellas se presenta un tipo particular de crisis con respecto a la orientación, dándose una tendencia de una alta deserción en los primeros tres semestres, la cual disminuye notablemente al final de la carrera.

En el primer ciclo (semestres I, II, III), donde la crisis que emerge se relaciona con un orden vocacional, hemos encontrado que en los procesos de orientación realizados con los bachilleres se da una gran cantidad de información sobre el rol laboral / profesional, lo que hace que el joven en sus primeros semestres de la carrera no encuentre el sentido de la formación disciplinar, que en muchos planes de estudios universitarios está fuertemente presentes en los primeros semestres. En este sentido nuestra propuesta está orientada a que en este primer ciclo las universidades ofrezcan a los estudiantes estrategias que le permitan seguir tomando la decisión, donde el joven vea la relación y pertinencia de lo disciplinar con lo laboral / profesional y de qué manera sus dimensiones personales se enriquecen con dicho proceso.

En el segundo ciclo (semestres IV, V, VI, VII), pareciera que aparece la crisis profesional, ésta hace referencia a la preocupación del joven por definir los campos o las áreas en las que se podría desempeñar; fijémonos cómo 
vuelve a aparecer un proceso que implica una toma de decisión, aquí el reto está encaminado a que el joven logre conectar su opción vocacional con su proyecto de vida laboral, es decir, tendríamos que acompañarlo, invitándolo a reflexionar sobre cómo el mundo profesional le abre perspectivas de vida a nivel personal, familiar, social, cultural y económicas, en las que él tendrá que evaluar la coherencia entre su rol profesional y su sentido humano.

En el tercer ciclo (semestres VIII, IX y X), nuevamente el joven se enfrenta a un proceso de toma de decisión que da cuenta de encontrar un lugar en el mundo del trabajo que haga posible el proyecto de vida que ha venido estableciendo; hoy en Colombia observamos con preocupación la poca posibilidad de acceder al mundo del trabajo por parte de los profesionales recién egresados; en este sentido, la crisis da más cuenta de un nivel existencial y de subsistencia, que nos invita a acompañar al joven a desarrollar competencias encaminadas a construir empresa, vender servicios a partir de la búsqueda de nuevas oportunidades laborales, y no a optar por cambiar su sueño al no encontrar empleo, lo que de alguna manera alimenta la sensación del joven bachiller de acceder como un proceso de moratoria social (proceso transicional para acceder al mundo adulto), pero con una gran incertidumbre de que esta sea una posibilidad certera para un futuro interesante.

\subsection{Presupuestos sistémicos en el pro- ceso de orientación}

Para repensar la orientación es necesario que redefinamos los presupuestos con los cuales hemos venido concibiendo dicho proceso; la búsqueda de unos referentes sistémicos tiene la pretensión de generar un nuevo marco referencial que permita integrar las acciones y procedimientos que vienen realizando los orientadores en los diferentes contextos escolares; consideramos que una nueva perspectiva paradigmática permitirá integrar y conectar las innumerables actividades realizadas para dicho proceso.

Uno de los presupuestos orientadores hace referencia a las acciones ecológicas, con las que queremos dar cuenta de la forma en que los hallazgos en las pruebas sobre los intereses y las aptitudes de los estudiantes tienen un efecto no causal para definir un tipo de carrera en particular, sino que la claridad en lo vocacional implica diversos posibles efectos en varias vías; una primera es sobre si se elige una carrera, unos estudios formales en una organización educativa o se ingresa directamente al mundo del trabajo; una segunda posibilidad es reconocer la diversidad de formaciones, como técnicas, tecnológicas y universitarias; y una tercera implicación es sobre las prácticas profesionales socialmente validadas para un pleno desarrollo humano.

El presupuesto sobre el trabajo en equipos reflexivos nos invita a pensar que hay que reconocer la diversidad de actores (estudiantes, profesores, padres de familia) que participan con sus diferentes apreciaciones, experiencias y expectativas de lo que es lo profesional y lo laboral; ninguna de estas voces es más significativa que la otra, por el contrario, se validan en la medida en que al compartirlas mediante un proceso reflexivo crean nuevas posibilidades de toma de decisión en el joven. En ese sentido, la competencia para tomar decisiones en el joven da cuenta de poder conciliar estas diferentes voces de manera reflexiva y poder encontrar puntos que le permitan ver opciones para él.

Con respecto al presupuesto de las redes conversacionales implica que la construcción de una acción de orientación profesional está mediada por la capacidad de generar diferentes nodos integradores de los contextos implicados en la toma de la decisión; como ya hemos reconocido, hay una gran diversidad de voces, las cuales es importante reconocer, pero ellas están implicadas en contextos, en donde tienen referentes diversos pero no excluyentes para el joven. Por lo tanto, los nodos identificados en la red tienen la función de facilitar conexiones entre los diferentes contextos para generar nuevos diálogos, historias y prácticas de lo vocacional y profesional del joven.

La orientación requiere entenderse como una construcción interaccional, este presupuesto da cuenta de que este es un proceso continuo en los diferentes momen- 
tos de escolarización del estudiante (preescolar, primaria, secundaria, media vocacional, universitaria y mundo laboral), por lo tanto es importante reconocer el tipo de decisiones que cada momento de la formación requiere. Este sistema de decisiones lleva a reconocer que la competencia para tomar decisiones se va construyendo y reconstruyendo solamente en las interacciones con los otros, donde se le invita al estudiante permanentemente a que tome decisiones y reflexione sobre la forma en que lo va haciendo.

El último presupuesto hace referencia a la creación de escenarios contextuales, en el sentido en que se reconoce y valida que los escenarios sociales, culturales, familiares y de aprendizaje son las fuentes esenciales con las cuales los jóvenes se proyectan al futuro, porque allí se reconocen en sus limitaciones y potencialidades; por lo tanto, estos escenarios no son simplemente lugares, sino contextos facilitadores para la toma de decisión desde una puesta en juego de diversos referentes, como lo son lo emocional, lo cognoscitivo y lo pragmático.

\subsection{Comprensión desde la red social de la interacción joven orientación}

El centro de la red social es el joven en relación con el proceso de la toma de decisión en la orientación. En la investigación encontramos que el sistema con el que el joven se siente más cercano en el proceso de orientación es el grupo de amigos, de ellos recibe en su orden: guía cognitiva, regulación social, intercambio de información y apoyo emocional; lo que nos invita a reflexionar sobre la gran importancia que los jóvenes le dan a sus iguales en los consejos y recomendaciones sobre lo que se debe estudiar y la forma en que se toman decisiones en la vida. En este sentido, no podemos desconocer que los amigos comparten procesos cognoscitivos y afectivos propios de su generación y esto permite que sus voces tengan eco en el joven. Lo interesante sería conectar el mundo de los jóvenes con el mundo adulto, para que las voces de los adultos adquieran fuerza en el reconocimiento de la necesidad del acompañamiento del joven frente a la toma de la decisión y no sobre la decisión como tal.
La familia está ante un reto interesante, y es que pareciera que por no volverse impositiva con el joven sobre lo que él va a estudiar, ha asumido una postura muy respetuosa que pon una muy buena intención, en pro de la autonomía de su hijo (a), ha quedado marginada en el acompañamiento de la toma de decisión; su papel se ha centrado ofrecer apoyo material y de servicios e información, es decir, los padres manifiestan ofrecer apoyo económico para el pago de sus estudios universitarios o le ubican datos sobre carreras y universidades. Desde otra perspectiva, es necesario que los padres de familia se posicionen más activos y dinámicos, dado que sus experiencias de vida como jóvenes, estudiantes y seres humanos que toman decisiones en lo cotidiano, les hace suficientemente competentes para que compartan con sus hijos algunas pistas y claves que les han permitido tomas decisiones de forma contextualizada y eficaz. La familia tiene un recurso que es el apoyo emocional, el cual en este momento vital del joven es significativo y tiene una gran fortaleza e impacto en él para la toma de decisiones.

El colegio, a pesar de sus innumerables esfuerzos por ofrecer al joven gran cantidad de información y consejos, pareciera que genera en el joven un efecto de confusión, dado que le ofrecen un panorama general de las carreras profesionales o invitan a que profesionales compartan sus experiencias laborales, frente a lo cual el joven manifiesta no tener herramientitas para cotejar esa información y encontrar luces.

Es importante, entonces, que en los proceso de orientación que se diseñen se invite al joven a generar procesos reflexivos que le permitan ser más permeable entre los limites que hay en estos cuadrantes de la red y así encuentre sentido a la información que se le presenta para la toma de la decisión.

Los medios de comunicación se han posicionado al igual que los amigos de manera cercana a los jóvenes, manifiestan que estos les dan guía cognitiva e información, es decir, consejos, recomendaciones y sugerencias sobre lo que está de "moda" estudiar para ser un joven "exitoso". A pesar de ser el segundo sistema de influen- 
cia en la toma de decisiones, pareciera que los jóvenes cuestionan la veracidad de los mensajes presentados y se preocupan porque terminan siendo influenciados para la toma de las decisiones.

Las redes sociales se pueden convertir en una gran fuente de apoyo para que los jóvenes se vuelvan competentes en la toma de sus decisiones, esto se lograría si la red social ofrece diversidad de funciones en sus diferentes contextos, sobre todo si los limites entre cada cuadrante se hacen más permeables, para que la información que recibe el joven esté circulando en toda la red y no se convierta en un gestor de mayor confusión. Pareciera que la función que prevalece en las redes sociales en estos procesos de orientación es el suministro de información y no su conexión; por lo tanto, se deben diversificar las funciones de una manera flexible y coordinada, para que los diferentes contextos en momentos vitales del joven participen de manera diferente en el proceso mismo de la toma de decisión de acuerdo a su pertinencia.

\section{4 Órdenes de orientación en los jóvenes}

Son diferentes las intencionalidades que un orientador puede tener en el momento de realizar un proceso de orientación; por una parte está la pretensión de identificar las potencialidades de los estudiantes, por otra reconocer el posible nivel de estudios en el cual pueden entrar y finalmente reconocer las posibilidades laborales una vez termine bachillerato o los estudios postsecundarios.

Lo vocacional da la perspectiva tanto para definir los estudios como el campo laboral de un estudiante, lo que es posible dado el conocimiento de sus valores, intereses, actitudes, aptitudes y talentos.

La profesionalización se realiza en un contexto formal de escolarización, donde a través de diferentes niveles de estudio se logra una formación en un campo disciplinar y profesional particular, esto lo habilita para un nivel de práctica social específica. Por su parte el trabajo se identifica cuando el joven puede prospectivamente orientar sus potencialidades o formación hacia un campo ocupacional, un empleo o una incursión en el mundo de la productividad.

Por lo tanto, en los procesos de orientación, es necesario estar chequeando la relación que se va tejiendo entre lo profesional, lo vocacional y el mundo del trabajo, dado que estos tres órdenes no solo están presentes en la toma de decisión del joven, sino que a lo largo de su formación universitaria tendrá que irlos nutriendo de manera que se conviertan en un elemento dinamizador de esa formación.

\subsection{Comprensiones sistémicas ecológicas del proceso de orientación}

La red del joven está matizada por los sistemas y contextos sociales, culturales, políticos, económicos y gubernamentales, donde las acciones en micro tienen repercusiones en los contextos y los cambios en los sistemas más amplios tienen repercusiones en la persona. Es una relación retroactiva y dialógica entre lo simple y lo complejo.

Las políticas y prácticas de los diferentes contextos están en juego en el momento en que un joven decide tomar la decisión de elegir una profesión y el mundo del trabajo; el hecho de que no sea muy evidente tal influencia no quiere decir que no exista. Es importante evidenciarla, porque el orientador y el joven deben buscar develar las diferentes condiciones que están permitiendo u obstaculizando la toma de decisiones pertinentes para los sistemas involucrados.

Ecológicamente vemos que el micro, el meso y el exosistema están atravesados por dos mitos. El primero de ellos hace referencia a la desconexión en los niveles de participación de cada sistema respecto a la educación del joven y el segundo sobre la asignación de alguien dentro de cada sistema como el responsable en el proceso de orientación profesional.

Con respecto al primer mito, observamos que tanto la familia como la escuela y las universidades han privile- 
giado la estrategia de proveer información al joven, sin lograr generar procesos formativos para el manejo coordinado de la información, lo que generalmente confunde al joven, dado que se ve inundado de muchos datos y pocas conexiones entre los mismos, lo que los hace poco relevantes al momento de tomar la decisión.

Con respecto al segundo mito, observamos que hay una pauta de responsabilidades entre los diferentes sistemas involucrados en el proceso de orientación, es así que, en las relaciones universidad-colegio, se responsabiliza al colegio, en la relación colegio-familia, se responsabiliza al psicólogo, en la relación psicólogojoven, se responsabiliza al joven; con lo cual los señalados responsables terminan utilizando como única alternativa para el proceso de orientación el dar información al sistema que lo responsabiliza y al joven.

En la actualidad los fenómenos de globalización, internacionalización y crisis económica, como factores característicos del cronosistema, han alimentado un temor al fracaso que de manera general se presenta fuertemente en la red; al ser el joven el centro de la red, es él quien recibe con mayor presión de los otros sistemas dicho temor, por ello manifiesta miedo a fracasar no sólo con él mismo, sino de decepcionar a su familia, colegio y universidad.

Sería oportuno trabajar sobre la movilización de estos dos mitos generando alianzas en los contextos que participan en el mesosistema, particularmente en la tríada familia, colegio y universidad, de manera que se adelanten conversaciones para definir corresponsabilidades tanto en el suministro de información como en el manejo que se le debe dar, y sobre la forma en que cada uno debe acompañar en diferentes órdenes al joven para sacarle el mayor provecho y para que le dé pistas para la toma de la decisión.

La corresponsabilidad implica que los diferentes contextos estén atentos a sus relaciones, por ejemplo, el colegio y la universidad deben estar en un constante intercambio que permita diseñar estrategias conjuntas para formar en la toma de decisiones y culminar el proceso de orientación profesional, lo que implica el ajuste a la cultura universitaria por lo menos durante el primer año de vida universitaria; el colegio y la familia diseñar proyectos de orientación que empiecen desde el preescolar y que poco a poco le permitan al joven ir desarrollando competencias para la toma de decisiones de vida, y así conjuntamente ir identificando intereses y aptitudes vocacionales.

\subsection{Niveles de aprendizaje para la toma de decisiones}

La toma de decisiones la podemos identificar en tres niveles de acción, que van del más simple al más complejo; en el nivel I el joven toma sus decisiones con base en informaciones recibidas de los diferentes contextos, por lo tanto, es comprendido como un aprendizaje desde los contenidos; en el nivel II, el joven toma la decisión con base en la conexiones que logra realizar de la información de los diferentes contextos en los cuales está inmerso, es decir, un aprendizaje de sentidos; en el nivel III, el joven toma la decisión porque logra hacer una redefinición de lo que significa su proyecto vital personal, siendo un aprendizaje de la corresponsabilidad.

Por lo tanto, el orientador debe tener claro que en la orientación el nivel del contenido es importante pero no suficiente para la toma de decisiones, por lo que las ferias universitarias, las conferencias, las visitas a las universidades, entre otras, por sí solas, no tienen un impacto significativo en la toma de decisiones; cuando es comprendido como un proceso no lineal, sino circular entre los diferentes sistemas implicados (familia, escuela, sociedad y Estado), el joven encontrará que las comprensiones y orientaciones de uno u otro lo afectan no de manera jerárquica, sino de tal manera que todos se pueden considerar en la toma de decisiones.

Cuando el joven llega al nivel III, logra comprender que la toma de decisiones sobre su elección profesional y laboral implica en él una verdadera transformación personal, que es una elección de co-responsabili- 
dades y de implicaciones de diferentes órdenes, más allá de los personales. El cambio de epistemología es comprender que la vida implica un proceso constante de toma de decisiones, para las que requiere conectar entre sí las diferentes actividades que realiza y encontrarles un sentido, lo que, a su vez, le permite reconocer qué requiere seguir proyectando para tomar decisiones más contextualizadas y ecológicas.

\subsection{Comprensión de la orientación}

Nuestra propuesta está encaminada a focalizar al orientador como el nodo articulador de los procesos individuales y colectivos que se realizan con el joven para su orientación vocacional / profesional / laboral.

En cuanto a las funciones y las tareas del orientador, éste debe conciliar entre la calidad y cantidad de actividades que realiza, dado que, si no las conecta, en el sentido de una red donde participan docentes, padres de familia, amigos, comunidad y universidad, no se pueden potencializar.

El proceso de orientación implica conocerse así mismo, elegir una profesión, ingresar a una organización de educación superior, progresar en la vida universitaria y ubicarse laboralmente; esta continuidad está mediada por la capacidad del orientador para integrar los acuerdos desde la red en la cual participa el joven.

El orientador puede potencializar, como funciones prioritarias de la red: el apoyo emocional, entendido como la forma en que los jóvenes reciben y utilizan el acompañamiento de sus amigos, padres y maestros; la búsqueda de sentidos y conexiones de la información que recibe, para clasificarla, priorizarla, desecharla y decantarla; la prospectiva de las carreras y los campos laborales que dado el desarrollo del país son más probables y empatan con su desarrollo personal y profesional futuro; el desarrollo de competencias socio-afectivas, interaccionales y axiológicas que le permitan adaptarse y ajustarse a la cultura universitaria y laboral, realizando otras transacciones con la familia de acuerdo a su nueva condición de hijo universitario o trabajador.

\subsection{Toma de dediciones sistémicamente}

La toma de decisiones se caracteriza por ser un proceso reflexivo, generativo e intercontextual en el que coparticipan diversos actores. Es reflexivo en cuanto el joven se ubica a sí mismo como foco de observación, y logra, por tanto, una mirada sobre cómo y desde dónde está tomando la decisión; es generativo, dado que está construyendo y reconstruyendo todo el tiempo su propia decisión, desde sus interacciones con la red en que participa; es intercontextual, ya que no se puede reconocer un solo sistema especial del cual el joven deba preferiblemente lograr tomar la decisión, al contrario, la decisión es producto de hacer conexiones y reconexiones de las informaciones de toda su red.

\subsection{Los padres en el proceso de orientación}

La visibilidad de los padres en el acompañamiento del proceso de orientación de los hijos responderá al interjuego permanente de dar autonomía y confiar en los recursos y capacidades de su hijo, para que a través de un seguimiento y chequeo del proceso, evalúen contextual e intercontextualmente lo que siente, piensa y hace para la toma de la decisión, así le está dando rutas para lo que debe seguir haciendo y le permite encontrar algunas bases claves para tomar de manera segura la decisión.

En este sentido, los padres deben participar haciéndose muy visibles en el proceso de la toma de decisión y poco visibles en la decisión como tal, dado que, entre más presentes estén en el camino recorrido por su hijo, más le permitián ganar en autonomía y confianza, condiciones necesarias para que los jóvenes realicen procesos reflexivos permanentes sobre la competencia de estar decidiendo. 


\section{Bibliografía}

(2003). Legislación educativa 2001-2002. Bogotá: Magisterio, Colección Documentos.

Ander, Ezequiel (1998). Educación y prospectiva. Buenos Aires: Magisterio del Río de la Plata.

Bisquerra, Fafael (1996). Orígenes y desarrollo de la orientación psicopedagógica. Madrid: Nancea.

Bloch, Donal (1985). “Terapia familiar y formación”. En Formaciones y prácticas en terapia familiar.

Bradford P., Keeney (1994). Estética del cambio. Barcelona: Paidós.

Cirillo, Stefano (1994). El cambio en contextos no terapéuticos. Barcelona: Paidós.

Coffey, Amanda y Atkinson, Paul (2003). Encontrar el sentido a los datos cualitativos: estrategias complementarias de investigación. Medellín: Universidad de Antioquia.

Dabas, E. N. (1993). Red de redes, las prácticas de la intervención en redes sociales. Buenos Aires: Paidós.

Dallos, Rudi (1996). Sistema de creencias familiares: terapia y cambio. Barcelona: Paidós.

Delors, Jacques (1996). La educación encierra un tesoro. Madrid: Santillana.

Elkaim, M. (1989). Las prácticas de la terapia de red. Barcelona: Gedisa

Elkaim, Mony (Compilador), (1988). Formaciones y prácticas en terapia familiar. Buenos Aires: Nueva Visión.

Folger, J. y Jones, T. (Compiladores), (1997). Nuevas direcciones en mediación: investigación y perspectivas comunicacionales. Buenos Aires: Paidós.
Gómez, B. H. (Director), (1998). Educación: La agenda del siglo XXI. Bogotá: PNUD-TM.

González Maura, Viviana (2001). "El servicio de orientación vocacional - profesional de la universidad de la Habana: una estrategia educativa para la elección y desarrollo profesional responsable del estudiante". En: Revista Pedagógica Universitaria, Vol. 6, No. 4. La Habana: Universidad de la Habana.

Gracia F., Enrique y Musitu O., Gonzalo (2000). Psicología social de la familia. Barcelona: Paidós.

Hernández, Ángela (1997). Familia, ciclo vital y psicoterapia sistémica breve. Bogotá: El Búho.

Imber-Black, Evan (2000). Familias y sistemas amplios: el terapeuta familiar en el laberinto. Buenos Aires: Amorrortu.

Jaes F., Celia (1992). Transiciones de la familia: continuidad y cambio en el ciclo de vida. Buenos Aires: Amorrortu.

Jay, Haley (1994). Terapia no convencional. Buenos Aires: Amorrortu.

Ministerio de Educación Nacional (1996). Educación para la democracia, el desarrollo, la equidad y la convivencia: Plan decenal de educación 1996-2005. Bogotá.

Mora, Antonio Juan (1998). Acción tutorial y orientación educativa. Madrid: Nancea, $5^{a}$. Ed.

Morin, E. (1994). Introducción al pensamiento complejo. Barcelona: Gedisa.

Pakman, Glasersfeld, Jorgenson, Maturana, Schön, Shotter y Steier (1996). Construcciones de la experiencia humana (Volumen I). Barcelona: Gedisa. 
Presidencia de la República de Colombia; Consejería para la modernización del Estado, conciencia, y Misión ciencia, educación y desarrollo (1994). Colombia al filo de la oportunidad. Bogotá.

República de Colombia. Ley 80 de 1993: Estatuto General de Contratación de la Administración Pública.

Revista Perspectivas Sistémicas (2000), Año 12, No. 60 , marzo-abril. Argentina.

Schvarstein, Leonardo (1992). Psicología de las organizaciones. Buenos Aires: Paidós.

Sluzki, C. (1996). La red social: fronteras de la práctica sistémica. Barcelona: Gedisa.
Speck, R., y Attneave, C. (1973). Redes. Buenos Aires: Amorrortu.

Universidad Nacional de Colombia. Memorias del 1er Congreso Internacional de Tutores y Consejeros en la Educación Superior, octubre 11 y 12 de 2004. Bogotá: Universidad Nacionall.

Universidad Santo Tomás (1997). Revista Aportes a la Psicología: Paradigmas emergentes, pensamiento complejo e intervención - investigación en los escenarios familiares. Año 3, No. 6. Bogotá: Universidad Santo Tomás.

Urie, Bronfenbrenner (1988). La ecología del desarrollo humano. Barcelona: Paidós. 